\title{
Identification and Solvent Extraction-Sedimentation Removal of Metallic Elements in Coal Tar Pitch
}

\author{
Lijuan $\mathrm{Gao}^{\mathrm{a}}$, Xiaojun Zheng, Yaming Zhu Xuefe Zhao ${ }^{\mathrm{b}}$ \\ Engineering research center of advanced coal coking and efficient use of coal resources, University \\ of Science and Technology Liaoning, Liaoning, Anshan 114051 \\ aemail gli62@sina.com, bemail zhaoxuefei@sohu.com,
}

\begin{abstract}
Keywords: coal tar; medium-temperature pitch; refined pitch; modified pitch; ICP-AES
Abstract. Refined pitches were obtained by distillation and solvent extraction with raw materials of the high temperature coal tar and medium-temperature pitch, respectively. Modified pitches were achieved by air oxidation treatment of refined pitches. Inductively Coupled Plasma-Atomic Emission Spectrometry (ICP-AES) was used to determine metallic elements of raw material and the prepared pitches. The results show that both the coal tar and medium-temperature pitch have metallic elements as follow: $\mathrm{Ge}, \mathrm{Pb}, \mathrm{Ba}, \mathrm{Mg}, \mathrm{Ce}, \mathrm{Cd}, \mathrm{Na}, \mathrm{Sn}, \mathrm{Zn}, \mathrm{Ni}, \mathrm{Bi}, \mathrm{Nb}, \mathrm{Be}, \mathrm{Cr}, \mathrm{Ca}, \mathrm{V}, \mathrm{In}, \mathrm{Ti}, \mathrm{Sr}, \mathrm{Si}, \mathrm{Cu}, \mathrm{Al}, \mathrm{Fe}$ and $\mathrm{Mn}$, among which the abundance of $\mathrm{Pb}, \mathrm{Mg}, \mathrm{Zn}, \mathrm{Ni}, \mathrm{Cr}, \mathrm{Ca}, \mathrm{Si}, \mathrm{Cu}, \mathrm{Al}, \mathrm{Fe}$, and $\mathrm{Mn}$ were relatively larger. The content of $\mathrm{Pb}, \mathrm{Cu}, \mathrm{Mn}, \mathrm{Zn}, \mathrm{Cr}, \mathrm{Ni}$ and $\mathrm{Mg}$ of coal tar were larger than those of the medium-temperature pitch, while the content of $\mathrm{Ca}, \mathrm{Al}$ and $\mathrm{Fe}$ were opposite. The content of all metallic elements decreased during the process of solvent extraction, while increased during the modification of refined pitch. Compared with the refined pitch prepared by solvent extraction, the content of metallic elements in coal tar refined pitch were higher. With the treatment of air oxidation, the metallic elements in modified medium-temperature pitch and modified coal tar pitch were similar except $\mathrm{Zn}$. Obviously, the modified coal tar pitch has a larger content of $\mathrm{Zn}$.
\end{abstract}

\section{Introduction}

Coal tar pitch is a kind of by-product of coke making or coal gas production, a residue after distilling various oiliness of coal tar. The coal tar pitch with soften point of $75^{\circ} \mathrm{C}-90{ }^{\circ} \mathrm{C}$ is medium-temperature pitch. Because of the high content of carbon, coal tar pitch is an important precursor of carbon and graphite materials, [1] such as needle coke ,carbon fiber, cladding pitch of lithium ion battery electrode material and so on.[2-4] Coal tar pitch contains various metallic elements inherited from the coal,[5] likewise, the prepared materials contain the same metallic elements. For example, content analysis of metal ion in the domestic carbon fiber showed a high content of impurities, especially higher content of metal ion of $\mathrm{Al}, \mathrm{Fe}, \mathrm{Ca}, \mathrm{Zn}, \mathrm{Cu}$ and $\mathrm{Mg}$.[6] The research on the catalytic mechanism of metal ions indicated that metal ions affect the carbon fiber structure and performance.[7] Carbon fiber is a defects-control brittle material. All kinds of defects would reduce the tensile strength and modulus of carbon fiber.[8] Introduced from raw materials and preparation process, the metal impurities of carbon fiber not only catalyze the oxidation of carbon, but also escape and leave holes during the process of high temperature carbonization. The catalytic graphitization function of the introduced metal impurities in the carbon fiber declines the graphitization temperature, thus increasing the modulus and reducing the strength of carbon fibers which are graphitized at lower temperature, e.g. carbonization temperature.[6-8] Therefore, it is necessary to study the metal ions and their distribution in the coal tar pitch. At present, the published analysis methods of metal elements in coal are spectrophotometry, [9-11] potentiometric titration,[12] inductively coupled plasma-atomic emission spectrometry (ICP-AES)[13,14], etc. In this paper, the refined pitch were obtained from the raw materials of coal tar and medium-temperature pitch, respectively, and further were subjected to be modified by air oxidation to prepare spinnable pitch. Tested by ICP-AES, the distributions of metal elements in the raw materials and each pitch were used to not only study the effects of trace amounts of metal elements on the properties of carbon fibers, but also providing practice foundation for removal of metal elements during the production of spinnable pitch. 


\section{Experimental}

\section{Raw materials}

Table 1 is the parameters of high-temperature coal tar (Ningxia Xitai Chemical Co., Ltd) and medium-temperature pitch (Angang Chemical Co., Ltd).

\section{Preparation of samples}

Sample 1\# (coal tar soft pitch) was obtained with softening point (tour) below $30{ }^{\circ} \mathrm{C}$ and yield of $80.44 \%$ by atmospherically distilling the high-temperature coal tar until gas temperature reaching 270 ${ }^{\circ} \mathrm{C}$. Sample 2\# was the medium-temperature pitch from Angang Chemical Co., Ltd. Sample 3\# (refined coal tar pitch) and sample 4\# (refined medium-temperature pitch) were obtained respectively from sample 1\# and sample 2\#, by following steps: At the temperature of $130{ }^{\circ} \mathrm{C}$, mixing the sample $1 \#$ and extraction at the ratio of 1:0.8 for 130 minutes. Then the mixture was settled for 8 hours (for sample $3 \#)$ and 2 hours (for sample 4\#) to separate the light phases, which accounting for $60 \% \sim 65 \%$ of the total quantity. Finally, vaporizing and eliminating the solvent. Sample 5\# (modified coal tar pitch) and sample 6\# (modified medium-temperature pitch) were obtained respectively from sample 3\# and sample $4 \#$ by air oxidation with air mass flow of $600 \mathrm{ml} \cdot \mathrm{min}-1$ at $280{ }^{\circ} \mathrm{C}$ for 8 hours.

\section{Test of metal elements in pitches}

\section{The preparation of sample solution to be tested}

(1) Preparation of pitch ash: a certain amount of sample 1\# 6\# put in respective cupels were heated in electric furnace until no black smoke, and then transferred into the muffle furnace $\left(800{ }^{\circ} \mathrm{C}\right)$ for about 4 $\mathrm{h}$ until pitch ash forming to weight and calculate the yield.

(2) Preparation of sample stock solutions: the mixture of pitch ash and lithium tetraborate (mass ratio of 1:5) put in a platinum crucible were heated in the muffle furnace at $1000{ }^{\circ} \mathrm{C}$ for 20 minutes. After being cooled, the mixtures dissolved in the $5 \%$ nitric acid solution completely by heating and mixing within a magnetic stirring apparatus. The dissolved samples were moved to the volumetric flasks for cooling and fixing the volume, and then transferred to the plastic bottle for ICP-AES measurement.

\section{Identification of metal ions in sample solution}

(1) Identifying the species of metal elements in samples 1\# and 2\# by spectrographical method.

(2) Quantitative determination of the content of metal ions by ICP-AES:

After the blank sample being tested, the diluted samples were introduced into plasma by atomizer to be analyzed. By comparing the measurement results and internal standard curves, the content of metal elements in asphalt were calculated.

Table 1 Index parameters of each pitch

\begin{tabular}{lllllll}
\hline Index parameters & $\mathrm{QI} / \%$ & $\mathrm{TI} / \%$ & $\mathrm{SP} /{ }^{\circ} \mathrm{C}$ & $\mathrm{CV} / \%$ & yield/\% & $\mathrm{Ash} / \%$ \\
\hline 1 \# (coal tar soft pitch) & 1.66 & 10.11 & 34.0 & 38.09 & 80.44 & 0.1162 \\
2\# (medium-temperature pitch) & 3.93 & 26.20 & 73.0 & 50.61 & -- & 0.0974 \\
3\# (refined coal tar pitch) & 0.063 & 6.86 & 24.5 & 30.81 & 63.0 & 0.0842 \\
4\# (refined medium-temperature pitch) & 0.68 & 42.22 & 69.0 & 56.46 & 64.0 & 0.0450 \\
5\# (modified coal tar pitch) & 5.96 & 53.91 & 275.0 & 76.45 & 60.8 & 0.1333 \\
6\# (modified medium-temperature pitch) & 15.34 & 55.41 & 246.2 & 71.39 & 63.2 & 0.1349 \\
\hline
\end{tabular}

\section{Results and Discussion}

\section{Qualitative analysis of spectrographical method.}

The result of spectrographical method showed that both sample $1 \#$ and 2\# had the metal ions of $\mathrm{Ge}, \mathrm{Pb}$, $\mathrm{Ba}, \mathrm{Mg}, \mathrm{Ce}, \mathrm{Cd}, \mathrm{Na}, \mathrm{Sn}, \mathrm{Zn}, \mathrm{Ni}, \mathrm{Bi}, \mathrm{Nb}, \mathrm{Be}, \mathrm{Cr}, \mathrm{Ca}, \mathrm{V}, \mathrm{In}, \mathrm{Ti}, \mathrm{Sr}, \mathrm{Si}, \mathrm{Cu}, \mathrm{Al}, \mathrm{Fe}$ and $\mathrm{Mn}$, among which the content of $\mathrm{Pb}, \mathrm{Mg}, \mathrm{Zn}, \mathrm{Ni}, \mathrm{Cr}, \mathrm{Ca}, \mathrm{Si}, \mathrm{Cu}, \mathrm{Al}, \mathrm{Fe}$ and $\mathrm{Mn}$ were relatively larger.

\section{Build standard working curve of the metallic elements}

The related equations and conditions of standard working curves for corresponding metal ions were listed in Table 2. 
Table 2 Standard working curves equation of metal ions

\begin{tabular}{ccc}
\hline Metal ions & $\lambda($ wave length $) / \mathrm{nm}$ & Standard working curves equation \\
\hline $\mathrm{Pb}$ & 220.353 & $\mathrm{I}=15.21(\mathrm{C} / \mathrm{ppm})+3.488, \mathrm{R}=0.9973$ \\
$\mathrm{Fe}$ & 396.152 & $\mathrm{I}=36.291(\mathrm{C} / \mathrm{ppm})-10.03, \mathrm{R}=0.9994$ \\
$\mathrm{Cu}$ & 324.754 & $\mathrm{I}=144.49(\mathrm{C} / \mathrm{ppm})+5.553, \mathrm{R}=0.9997$ \\
$\mathrm{Mn}$ & 257.610 & $\mathrm{I}=195.96(\mathrm{C} / \mathrm{ppm})+3.789, \mathrm{R}=0.9953$ \\
$\mathrm{Zn}$ & 213.856 & $\mathrm{I}=24.378(\mathrm{C} / \mathrm{ppm})+56.26, \mathrm{R}=0.9993$ \\
$\mathrm{Cr}$ & 267.716 & $\mathrm{I}=51.575(\mathrm{C} / \mathrm{ppm})+3.964, \mathrm{R}=0.9946$ \\
$\mathrm{Ni}$ & 221.647 & $\mathrm{I}=7.511(\mathrm{C} / \mathrm{ppm})+4.722, \mathrm{R}=0.9972$ \\
$\mathrm{Al}$ & 396.152 & $\mathrm{I}=36.291(\mathrm{C} / \mathrm{ppm})-10.03, \mathrm{R}=0.9994$ \\
$\mathrm{Mg}$ & 279.553 & $\mathrm{I}=1166.78(\mathrm{C} / \mathrm{ppm})+429.82, \mathrm{R}=0.9991$ \\
$\mathrm{Ca}$ & 393.366 & $\mathrm{I}=6116.66(\mathrm{C} / \mathrm{ppm})+1631.1, \mathrm{R}=0.9996$ \\
$\mathrm{Si}$ & 251.611 & $\mathrm{I}=251.611(\mathrm{C} / \mathrm{ppm})-80.93, \mathrm{R}=0.9963$ \\
\hline
\end{tabular}

\section{Quantitative analysis of the content of metal ions by ICP-AES}

The 6 samples in Table 1 were prepared into 6 probational solutions for testing under the conditions listed in Table 2. Figure 1, 2 and 3 are the quantitative analysis results of the content of metal ions by ICP-AES.
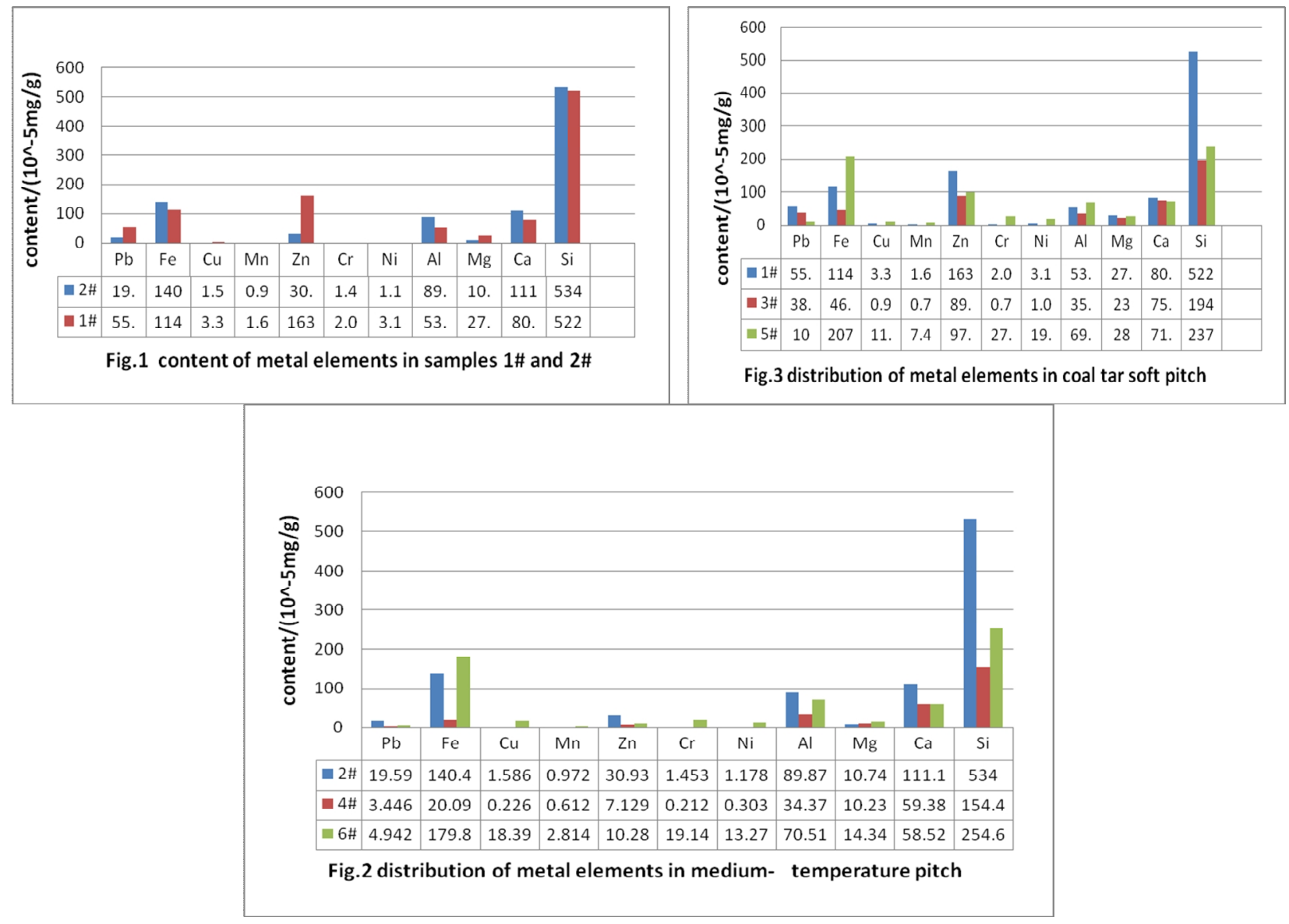

\section{Content analysis of metal elements during the technological process}

It can be seen from Figure 1, the content of $\mathrm{Pb}, \mathrm{Cu}, \mathrm{Mn}, \mathrm{Zn}, \mathrm{Cr}, \mathrm{Ni}$ and $\mathrm{Mg}$ in raw material of coal tar were higher than those in medium-temperature pitch, while the content of $\mathrm{Ca}, \mathrm{Al}$ and $\mathrm{Fe}$ in raw material of coal tar were less than those in medium-temperature pitch.

As shown in Figure 2 and Figure 3, the content of all metal elements reduced during the extracting purification, indicating its function of metal elements removal. The content of most metal elements 
increased during the modification process of refined pitch. Calculated from the data in Figure 2 and Figure 3, the removal rate of $\mathrm{Pb}, \mathrm{Cu}, \mathrm{Zn}, \mathrm{Cr}, \mathrm{Ni}, \mathrm{Al}, \mathrm{Ca}, \mathrm{Fe}$ and $\mathrm{Si}$ of medium-temperature pitch $(82.4 \%, 85.8 \%, 77 \%, 85.4 \%, 74.3 \%, 61.7 \%, 46.6 \%, 85.7 \%, 71.1 \%)$ was larger than that of coal tar raw material $(29.9 \%, 70.7 \%, 44.7 \%, 63.9 \%, 66.2 \%, 34.2 \%, 6.6 \%, 59.1 \%, 62 \%)$, while the removal rate of $\mathrm{Mn}$ and $\mathrm{Mg}$ of medium-temperature pitch (37\% and 4.7\%) was less than that of coal tar raw material (4.7\% and 15.2\%), indicating the process with raw material of medium-temperature pitch was better.

\section{Conclusions}

(1) Both the coal tar and medium-tempreature pitch had the metal elements of $\mathrm{Ge}, \mathrm{Pb}, \mathrm{Ba}, \mathrm{Mg}, \mathrm{Ce}$, $\mathrm{Cd}, \mathrm{Na}, \mathrm{Sn}, \mathrm{Zn}, \mathrm{Ni}, \mathrm{Bi}, \mathrm{Nb}, \mathrm{Be}, \mathrm{Cr}, \mathrm{Ca}, \mathrm{V}, \mathrm{In}, \mathrm{Ti}, \mathrm{Sr}, \mathrm{Si}, \mathrm{Cu}, \mathrm{Al}, \mathrm{Fe}$ and $\mathrm{Mn}$, among which the abundance of $\mathrm{Pb}, \mathrm{Mg}, \mathrm{Zn}, \mathrm{Ni}, \mathrm{Cr}, \mathrm{Ca}, \mathrm{Si}, \mathrm{Cu}, \mathrm{Al}, \mathrm{Fe}$ and $\mathrm{Mn}$ were larger. The content of $\mathrm{Pb}, \mathrm{Cu}, \mathrm{Mn}$, $\mathrm{Zn}, \mathrm{Cr}, \mathrm{Ni}$ and $\mathrm{Mg}$ in coal tar were larger than those in medium-temperature pitch, while the $\mathrm{Ca}, \mathrm{Al}$ and $\mathrm{Fe}$ were the opposite.

(2) The content of all metal elements reduced when using solvent extraction and subside, while increased when using air oxidation modification. The metal ions removal result of solvent extraction and subside showed that the removal ratio of $\mathrm{Pb}, \mathrm{Cu}, \mathrm{Zn}, \mathrm{Cr}, \mathrm{Ni}, \mathrm{Al}, \mathrm{Ca}, \mathrm{Fe}$ and $\mathrm{Si}$ in medium-temperature pitch were larger than those of coal tar, while the $\mathrm{Mn}$ and $\mathrm{Mg}$ were the opposite, indicating the process with raw material of medium-temperature pitch was better.

(3) Using solvent extraction and subside, the refined pitch obtained from the coal tar had larger content of metal ions than the counterpart obtained from medium-temperature pitch. Modified by air oxidation, the modified medium-temperature pitch and modified coal tar pitch had the similar content of each metal ions except $\mathrm{Zn}$, the content of which was larger in modified coal tar pitch.

\section{Acknowledgements}

This work was financially supported by the Natural Science Foundation of China ( U1361126) and the Specialized Research Fund for the Doctoral Program of Higher Education (20132120110001).

\section{References}

[1] S.Ramjee, B. Rand, W.W. Focke. Carbon, Vol. 82 (2015), P. 368.

[2] G. Bhatia, E. Fitzer, D. Kompalik. Carbon, Vol. 24 (1986), p. 489.

[3] I. Mochida, S.H. Yoon, N. Takano, et al. Carbon, Vol. 34 (1996), p. 941.

[4] Y.J. Han, J. Kim, J.S. Yeo, et al. Carbon, Vol. 94 (2015), p. 432.

[5] C.M. Xu, S.Q. Zhao, C.X. lu, et al. CIESC Journal, Vol. 61 (2010), P.2393.

[6] J.R. Wang, Z.J. Yang. Yunnan Metallurdy, Vol. 41 (2012), p. 85.

[7] C.Q. Li, S.G. Xu, Y.J. Tong, et al. Hi-tech Fiber\&Application, Vol. 31 (2006), p. 17.

[8] C.Q. Li, S. Yuan, H. Liu, et al. Journal of Beijing Uninversity of Chemical Technology (Natural Science), Vol. 36 (2009), p. 40.

[9] D.C. Luo, L.B. Ning. Metallurgical Analysis, Vol. 26 (2006), p. 14.

[10] N.D. Huang, C.B. Xia. Journal of instrumenta Analysis, Vol.19 (2000), p.52.

[11] D.C. Luo, J.F. Liu. Metallurgical Analysis, Vol. 30 (2010), p. 54.

[12] D.S. He, X.Y. Xu, R.A. Chi, et al. Non-ferrous Mining and Metallurgy, Vol. 28 (2012), p. 88.

[13] W.F Zhou. Guizhou Geology, Vol. 27 (2010), p. 240.

[14]L.Tuo,H.J.Yang. Metallurgical Analysis, Vol. 32 (2012), p. 70. 